\title{
HISTOMORPHOLOGICAL VARIANTS OF NODAL LYMPHOMAS AT GANDHI HOSPITAL -A 2 YEAR PROSPECTIVE STUDY
}

\author{
P. Jijiya Bai, Sunethri Padma, B. Bheeshma, O. Sravan Kumar, Renuka
}

1. Professor \& HOD, Department of Pathology, Gandhi Medical College, Secunderabad, Andhrapradesh.

2. Assistant Professor, Department of Pathology, Gandhi Medical College, Secunderabad, Andhrapradesh.

3. Associate Professor, Department of Pathology, Gandhi Medical College, Secunderabad, Andhrapradesh.

4. Professor, Department of Pathology, Gandhi Medical College, Secunderabad, Andhrapradesh.

5. Post Graduate, Department of Pathology, Gandhi Medical College, Secunderabad, Andhrapradesh.

\section{CORRESPONDING AUTHOR}

Dr. Sunethri Padma

Department of pathology,

Gandhi Medical College,

Secunderabad, Andhrapradesh

E-mail: sunethripadma@yahoo.co.in,

Ph: 00919885830564.

ABSTRACT: Lymphomas are malignant neoplasms of lymphoid tissue. AIMS \& OBJECTIVES: The objective of the study was to evaluate the Histomorphological variants of Nodal lymphomas at Gandhi hospital for over a period of two years. Materials \& methods: We have studied 40 out of 220 nodal biopsies which revealed histomorphology of lymphoma. IHC markers were done to type the lymphomas Results: Out of 40 cases 31 were Non Hodgkins lymphomas (NHL) and 9 were Hodgkins .Follicular variant was the commonest one. CONCLUSION: NHL was the commonest nodal lymphoma at our hospital with Follicular lymphoma predominating. Typing of the lymphomas has prognostic implications and IHC is a useful ancillary technique in the diagnosis.

KEY WORDS: Non Hodgkins Lymphoma, Hodgkins Lymphoma, Immunohistochemistry, Variants of lymphoma

INTRODUCTION: Lymphomas are neoplasm of the lympho-reticular system and arise in the lymph node or extranodal sites. They affect all age groups. They constitute $5.6 \%$ of all the cancers. This is seventh common cancer in adults and third common in children. There are aggressive and indolent variants of lymphoma with varied clinical presentation and clinical outcome. In our study we have evaluated all the nodal biopsies with lymphoma and typed them accordingly using immunohistochemistry.

AIMS \& OBJECTIVES: Aim of the study was to evaluate and enumerate the Histomorphological variants of the Lymphomas in the nodal biopsies at department of pathology, Gandhi Hospital.

MATERIALS \& METHODS: The present study was a prospective study done at Gandhi hospital in the department of pathology for over a period of two years from May 2010 to May 2012.During this period we received a total of 220 lymph node biopsies from various sites. All these biopsies were grossed and tissue was processed routinely and H\&E stained sections were prepared. These sections were studied under light microscopy .Out of all the 220 lymph nodal biopsies, 40(18\%) revealed histological features of lymphoma .These cases formed our study group. All the clinical details were acquired for these cases. All the haematological parameters 
were evaluated in these patients including hemogram, bone marrow Aspiration and Bone Marrow Biopsy when needed. Relevant Immunohistochemistry markers were done for typing these lymphomas .All the results were complied and correlated for further evaluation.

RESULTS: $40(18 \%)$ out of total 220 biopsies revealed Histomorphological features of Lymphoma. Out of these 40,31(77\%) were diagnosed as Non Hodgkins Lymphoma (NHL) and the remaining $9(23 \%)$ as Hodgkins Lymphoma (HL). The diagnosis was done based on morphological features and Immunohistochemistry makers.

Amongst NHL, five variants were identified .They were Follicular lymphoma (FL), Diffuse large B cell lymphoma (DLBCL), Anaplastic lymphoma (AL), Precursor T cell lymphoma (PTCL) and Small cell Lymphoma (SLL).The age and sex distribution for each group of lymphoma is as follows:

Immunohistochemistry was done to arrive at a final diagnosis

Majority of the cases belonged to FL (61\%) with mean age of 53 years with male preponderance. DLBCL formed the second major group with $26 \%$ and male preponderance and a mean age of 53 years. Anaplastic lymphoma had two cases amounting upto $7 \%$ and mean age of 50 years. PTCL and SLL had one case each constituting $3 \%$ each and both the cases were males. All the cases of HL were of mixed type with a mean age of 43 and male preponderance. In NHL various groups of lymph nodes were involved and their distribution is as follows:

Most of the cases of FL were abdominal nodes and two cases had generalised lymphadenopathy. Most of the cases diagnosed as DLBCL also had abdominal nodes and one case presented with cervical lymphadenopathy and hepatosplenomegaly.AL had one patient with abdominal nodes and other with cervical lymphadenopathy. PTCL and SLL patients presented with cervical lymphadenopathy.

All cases of HL presented with cervical lymphadenopathy.

Peripheral smears of all the patients were normal except for one patient with FL had lymphocytosis. Bone marrow biopsy of this patient showed nodular infiltration of the marrow.

To summarise in our study Non Hodgkins lymphoma is the commonest type of Lymphoma in our study with Follicular variant forming the major category. All cases of Hodgkin's lymphoma were of mixed type.

Discussion: Lymphoma is the malignant neoplasm of the lymphoid tissue. In the present scenario, diagnosis of lymphomas is based on the criteria laid down by World health Organization(WHO) which in turn is determined according to the stratification of neoplasms depending on their precursor cell and clinical status(1). Preliminary diagnosis of lymphomas by light microscopy always remains the standard diagnostic modality (2).However the typing of these tumours needs immunophenotyping and flow cytometry. These neoplasms now are explored upto the molecular level and hence genetic alterations have a vital role in categorizing these tumours and their prognosis( ${ }^{(3)}$.However the extent to which the genetic alterations define the behaviour of the tumour is still questionable ${ }^{(4)}$.

In our study NHL constituted more number of cases than HL. These findings were similar to the study done by Arora $\mathrm{N}$ etal(5).However in their study majority of the cases of NHL were of Diffuse large B cell lymphoma type where as in our study we had more number of Follicular lymphomas(61\%).Follicular lymphoma is the neoplasm of germinal centre B cells and is commonly associated with inappropriate activation of protoncogene on chromosome 
18q21(6).Several risk factors like sedentary lifestyle, obesity, diet high in meat and milk were proved to be the risk factors to these lymphomas(7).

In our study Diffuse Large B cell lymphoma was the second major group of NHL. DLBCLs are aggressive B-cell lymphomas with varied clinical, pathological, and genetic aberrations ${ }^{(8)}$.To major extent these patients are cured but there is still mortality inspite of new therapeutic regimes ${ }^{(9)}$.Some authors have stated that BCL-6 is a marker of better prognosis and CD138 is a marker of poor prognosis for DLBCL patients(10).

We had two cases of anaplastic large cell lymphoma (7\%). Both the cases are Alk positive. These patients have a good prognosis when compared to ALK negative patients (11).

In our study we had one case each(3\%) of Precursor T cell Lymphoma and Small cell lymphoma. Precursor T cell lymphoma was Tdt positive and for diagnosis of this entity Tdt positivity is mandatory (12). The case of Small cell lymphoma in our study had generalised lymphadenopathy with splenomegaly. These cases have to be distinguished from Chronic lymphocytic leukemia. Both CLL and SLL are currently considered different manifestations of the same entity by the fourth edition of the World Health Organization Classification of Tumours of Haematopoietic and Lymphoid Tissues(13).

In our study we had 9 cases of Hodgkins lymphoma which accounted to 23\%.All the cases were of mixed type. These findings were similar to the study of Arora $\mathrm{N}$ etal(5).Studies have shown that single nucleotide pleomorphisms play a vital role in pathogenesis of Hodgkins lymphoma ${ }^{(14)}$.Hence gene targeted therapies are of utmost utility in these lymphomas.

The world Health Organization has classified and revised Lymphomas taking in to consideration the morphology, Immunophenotype, genetic features and clinical features(15).A careful diagnosis of type of lymphoma is desirable as it has got prognostic implications.The incidence of various variants of lymphomas in the population helps us to study the pattern of distribution of these malignancies and this may aid in formulating etiological factors there by the preventive measures. In this study we have made a similar effort and since our patients mostly belonged to low socioeconomic category we hypothesize environmental factors could be one of the major in etiology of Lymphomas.

CONCLUSION: Non -Hodgkins Lymphoma is more common than Hodgkins lymphoma Immunohistochemistry is mandatory for the diagnosis of these cases .A thorough workup of these cases is essential and identification of variants is important in prognosis and management of these cases.

\section{REFERENCES:}

1. Soldini D, Campo E New insights into the diagnosis of lymphomas Ann Oncol. 2012 Sep;23 Suppl 10:x83-x88.

2. 2. Ott $G$,Ziepert $M$, Klapper $W$, et al . Immunoblastic morphology but not the immunohistochemical GCB/non GCB classifier predicts outcome in diffuse large B-cell lymphoma in the RICOVER-60 trial of the DSHNHL. Blood 2010;116: 4916-4925

3. 3.Meyerson M,Gabriel S, Getz G. Advances in understanding cancer genomes through second-generation sequencing. Nat Rev Genet 2010; 11: 685-696.

4. Bakshi N, Maghfoor I The current lymphoma classification: new concepts and practical applications triumphs and woes. Ann Saudi Med. 2012 May-Jun;32(3):296-305

5. Arora N, Manipadam MT, Nair S Frequency and distribution of lymphoma types in a tertiary care hospital in South India: analysis of 5115 cases using the World Health 
Organization 2008 classification and comparison with world literature Leuk Lymphoma. 2012 Oct 1.

6. H Nogai,B Dorken and G Lenz, Pathogenesis of Non Hodgkins Lymphoma ,Journal of clinical oncology, Vol 29,no 14,pp 1803-1811,2011

7. 7.AmdinderAJ Shenoy PJ, Malik $\mathrm{N}$, Exploring risk factors for Follicular lymphoma,Adv Hematol.2012;2012:626035

8. Menon MP, Pittaluga S, Jaffe ES. The histological and biological spectrum of diffuse large B-cell lymphoma in the world health organization classification Cancer J. 2012 Sep;18(5):411-20.

9. Jonathan W. Friedberg New strategies in diffuse large B-cell lymphoma: Translating findings from gene expression analyses into clinical practice Clin Cancer Res. 2011 October 1; 17(19): 6112-6117

10. Bodoor K, Matalka I, Hayajneh RHaddad YBodoor Evaluation of BCL-6, CD10, CD138 and MUM-1 Expression in Diffuse Large B-Cell Lymphoma patients: CD138 is a Marker of Poor Prognosis. Asian Pac J Cancer Prev. 2012;13(7):3037-46.

11. Mussolin L, Damm-Welk C, Pillon M Use of minimal disseminated disease and immunity to NPM-ALK antigen to stratify ALK-positive ALCL patients with different prognosis Leukemia. 2012 Jul 18. doi: 10.1038/leu.2012.205

12. Terada T. TDT (-), KIT (+), CD34 (+), CD99 (+) precursor T lymphoblastic leukemia/lymphomaInt J Clin Exp Pathol. 2012;5(2):167-70. Epub 2012 Feb 12

13. Santos FP, O'Brien SSmall lymphocytic lymphoma and chronic lymphocytic leukemia: are they the same disease? Cancer J. 2012 Sep;18(5):396-403

14. MONROY CM, CORTES AC, LOPEZ M, HODGKIN lymphoma RISK: ROLE OF GENETIC POLYMORPHISMS AND GENE-GENE INTERACTIONS IN DNA REPAIR PATHWAYS.2011 NOV;50(11):825-34. DOI: 10.1002/MC.20747. EPUB 2011 MAR 3.

15. Tohda $S$ [Overview of lymphoid neoplasms in the fourth edition of the WHO classification]. Rinsho Byori. 2012 Jun;60(6):560-4.

\section{TABEL1 NON HODGKIN'S LYMPHOMA}

\begin{tabular}{|c|c|c|c|}
\hline Histological type & No of cases & Mean age & M:F \\
\hline FL & 19 & 53 & $2.8: 1$ \\
\hline DLBCL & 8 & 53 & $1.6: 1$ \\
\hline AL & 2 & 50 & $1: 1$ \\
\hline PTCL & 1 & 36 & M \\
\hline SLL & 1 & 52 & M \\
\hline
\end{tabular}

TABLE 2 HODGKIN'S LYMPHOMA

\begin{tabular}{|c|c|}
\hline No of cases & 9 \\
\hline Mean age & 43 \\
\hline M : F & $3.5: 1$ \\
\hline
\end{tabular}


TABLE 3 TYPING OF LYMPHOMAS BASED ON IHC MARKERS

\begin{tabular}{|c|c|c|c|c|c|c|c|c|c|c|c|}
\hline $\begin{array}{l}\text { Histological } \\
\text { type }\end{array}$ & $\begin{array}{l}\text { CD } \\
3\end{array}$ & $\begin{array}{l}\text { CD } \\
45\end{array}$ & $\begin{array}{l}\text { CD } \\
20\end{array}$ & $\begin{array}{l}\text { CD } \\
5\end{array}$ & $\begin{array}{l}\text { CD } \\
10\end{array}$ & $\begin{array}{l}\text { CD } \\
23\end{array}$ & $\mathrm{TdT}$ & $\begin{array}{l}\text { ALK } \\
-1\end{array}$ & $\begin{array}{l}\text { CD } \\
30\end{array}$ & Ki67\% & $\mathrm{Bcl} 2$ \\
\hline FL & - & + & & - & + & + & & & & $60 \%$ & $\begin{array}{l}+t \\
\text { (Nuclear) }\end{array}$ \\
\hline DLBCL & $\mathrm{F}+$ & $\mathrm{D}+$ & $\mathrm{D}+$ & - & + & - & & & & $80 \%$ & \\
\hline ALCL & + & + & - & - & - & & & + & + & $80 \%$ & \\
\hline PTLL & & & & & & & & & & $40 \%$ & \\
\hline SCLL & & & & & & & & & & $20 \%$ & \\
\hline
\end{tabular}

TABLE 4

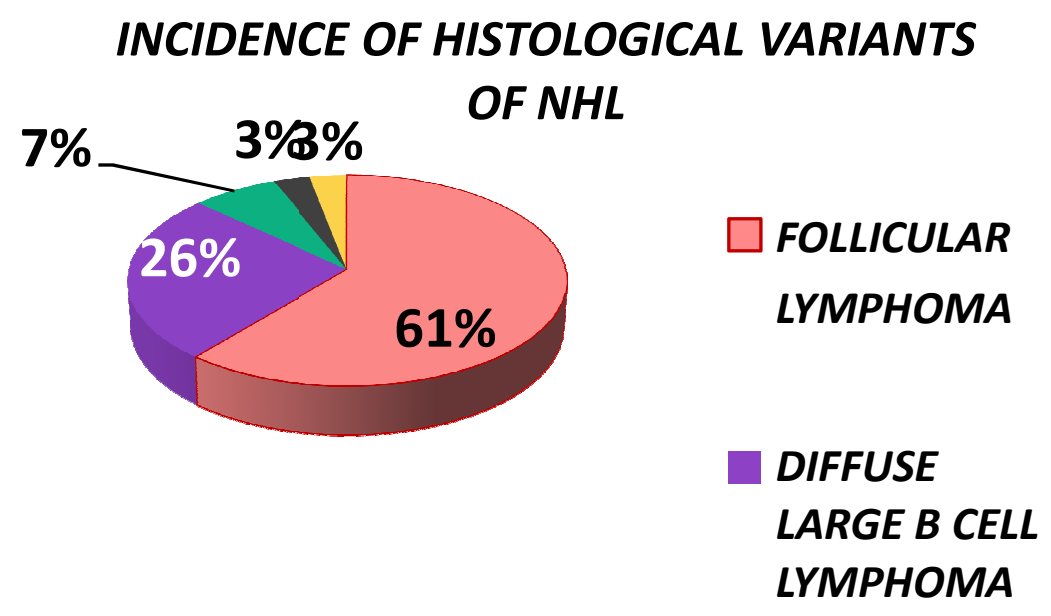

TABLE 5 GROUP OF LYMPHNODES INVOLVED

\begin{tabular}{|c|c|c|c|c|c|c|}
\hline \multirow{2}{*}{ LYMPHNODE GROUP } & \multicolumn{5}{|c|}{ NHL } & HL \\
\hline & FL & DLBL & AL & PTCL & SLL & \\
\hline Abdominal lymphnodes & 12 & 4 & 1 & & & \\
\hline Cervical lymphnodes & 4 & 3 & 1 & 1 & 1 & 9 \\
\hline Generalized Lymphadenopathy & 2 & 3 & & & & \\
\hline Cervical with Hepatosplenomegaly & & 1 & & & & \\
\hline Total & 19 & 8 & 2 & 1 & 1 & 9 \\
\hline
\end{tabular}




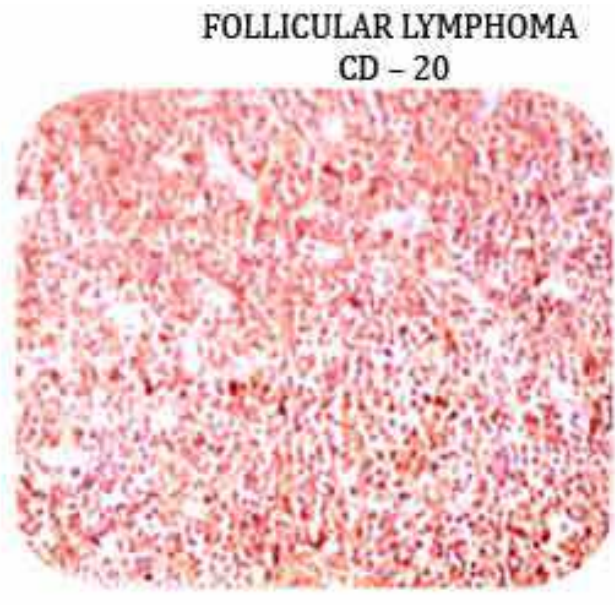

$40 \mathrm{X}$
BCL 2

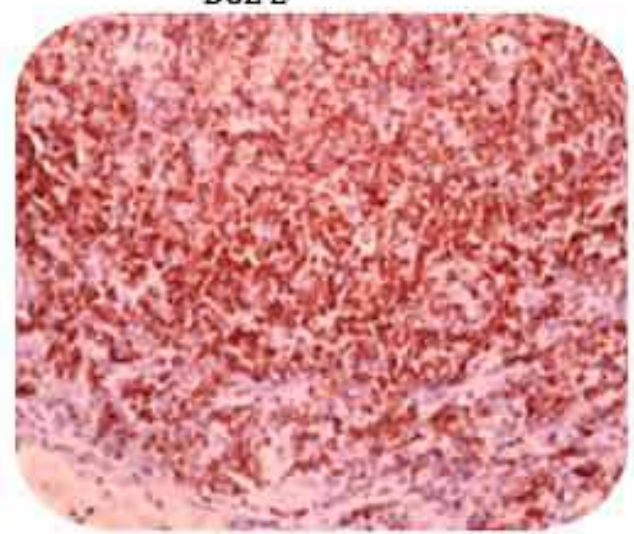

$40 \mathrm{X}$

\section{DIFFUSE LARGE CELL LYMPHOMA}

CD 3

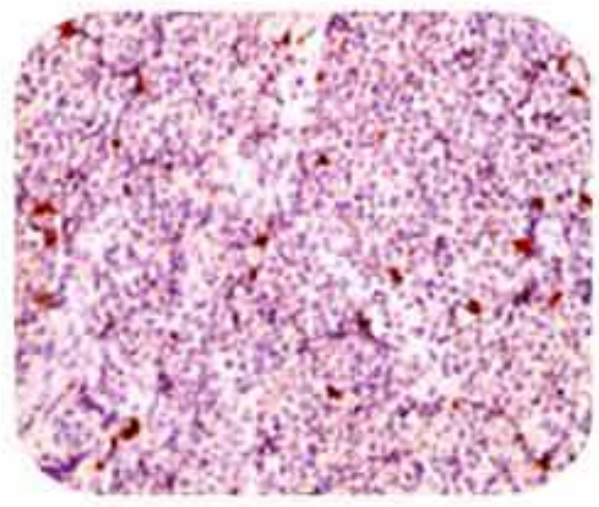

CD 20

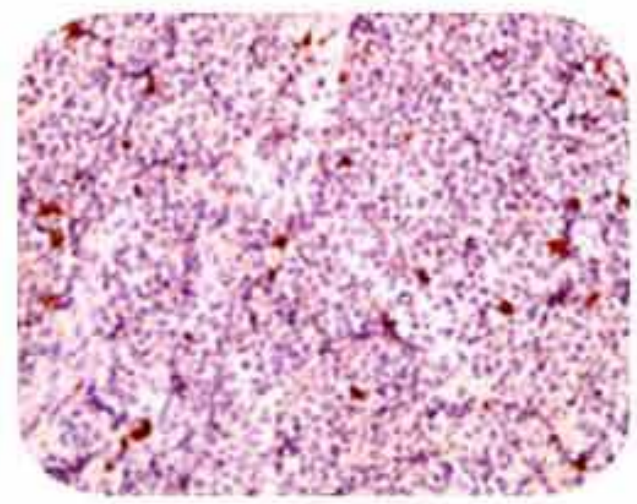




\section{ORIGINAL ARTICLE}

ANAPLASTIC LARGE CELL LYMPHOMA

CD 3

CD 30
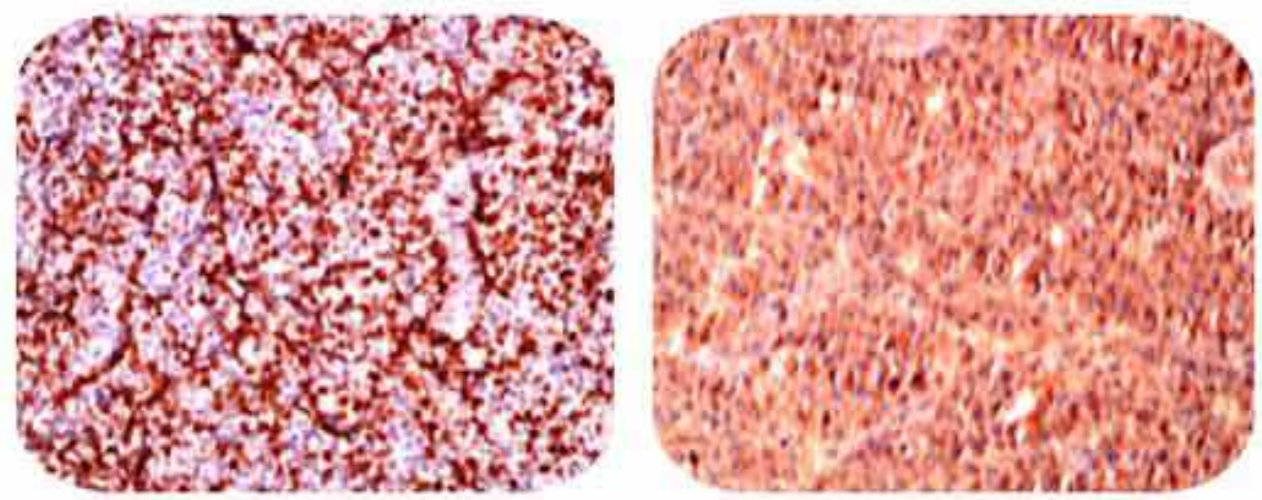

PRECURSER T CELL LYMPHOMA

ALK 1

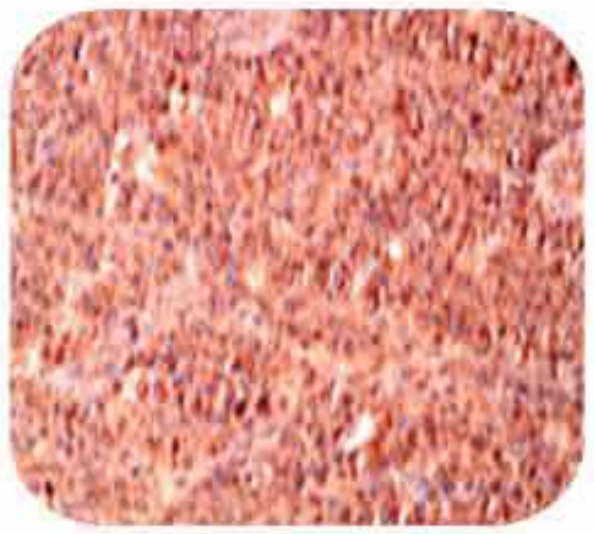

CD 30

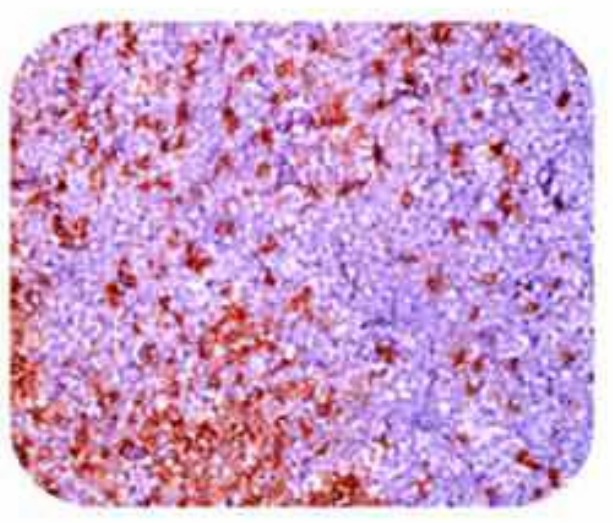

SMALL CELL LYMPHOMA

CD 20

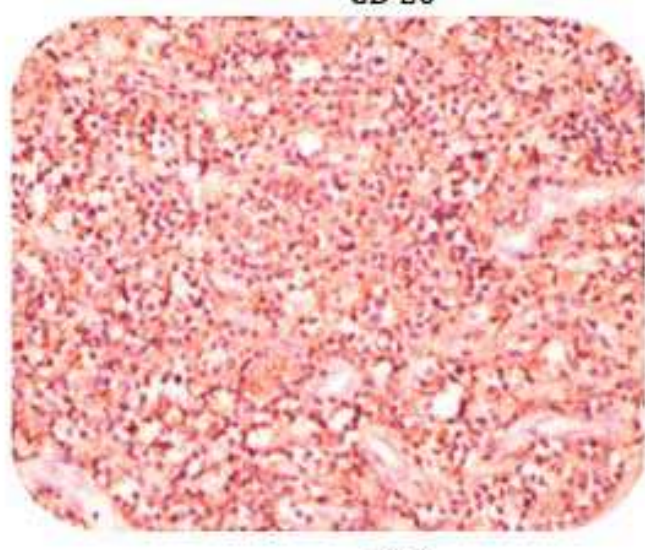

$40 \mathrm{X}$

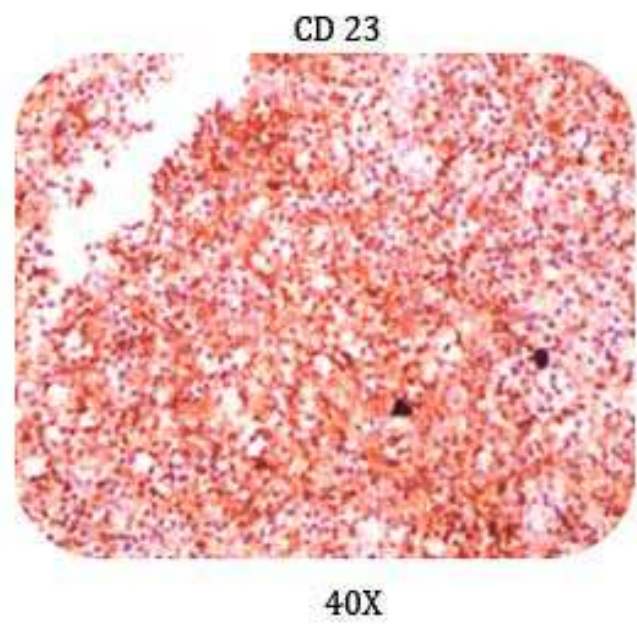

$40 \mathrm{X}$ 